\title{
Prediction of lamb body composition using in vivo bioimpedance analysis
}

\author{
by Moro, A.B., Pires, C.C., da Silva, L.P., Dias, A.M.O., \\ Pilecco, V.M., Mello, R. de O. and de Aguiar, L.K.
}

Copyright, Publisher and Additional Information: This is the author accepted manuscript. The final published version (version of record) is available online via Elsevier.

This version is made available under the CC-BY-ND-NC licence:

https://creativecommons.org/licenses/by-nc-nd/4.0/legalcode

Please refer to any applicable terms of use of the publisher

DOI: https://doi.org/10.1016/j.meatsci.2018.09.013

Moro, A.B., Pires, C.C., da Silva, L.P., Dias, A.M.O., Pilecco, Mello, R. de O. and de Aguiar, L.K. 2018.

Prediction of lamb body composition using in vivo bioimpedance analysis. Meat Science, 150 pp.1-6. 
1 Prediction of lamb body composition using in vivo bioimpedance analysis

2

3 Anderson B. Moro ${ }^{a, *}$, Cleber C. Pires ${ }^{a}$, Leila P. da Silva ${ }^{a}$, Ana M.O. Dias ${ }^{a}$, Robson R.

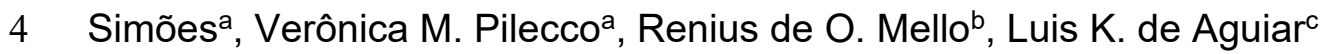

5

6 a Department of Animal Science, Federal University of Santa Maria, Avenida Roraima, 7 1000, Cidade Universitária, Bairro Camobi, 97105-900, Santa Maria, RS, Brazil

8 b Department of Food Science and Technology, Federal University of Santa Maria, 9 Avenida Roraima, 1000, Cidade Universitária, Bairro Camobi, 97105-900, Santa Maria, 10 RS, Brazil

11 c Department of Food Science and Agrifood Supply Chain Management, Harper Adams 12 University, Newport, Shropshire, TF10 8NB, England

$14{ }^{*}$ Corresponding author: Anderson Bortoluzzi Moro. Email:

15 andersondazoo@gmail.com

16

\section{Abstract}

The objective of this study was to evaluate the potential of in vivo bioimpedance analysis (BIA) as a method to estimate body composition in lambs. Thirty-one Texel $x$ lle de France crossbreed ram lambs were slaughtered at pre-determined intervals of average weights of $20,26,32$, and $38 \mathrm{~kg}$. Before the slaughter of the animals, their body weight (BW) and body length $(B L)$ were measured. The values for resistance $(R s)$ and reactance $(\mathrm{Xc})$ were collected using a single-frequency BIA equipment (Model RJL Quantum II Bioelectrical Body Composition Analyzer). The BIA main variables such as body bioelectrical volume $(V)$, phase angle $(P A)$, resistive density $(R s D)$, and reactive density $(X c D)$ were then 
calculated. The soft tissue mass of the right-half cold carcass was analyzed in order to determine its chemical composition. Multiple regression analyses were performed using the lamb body composition as dependent variables and the measurements related to bioimpedance as independent variables. The best regression models were evaluated by cross-validation. The predictive model of moisture mass, which was developed by using $\mathrm{XcD}$ and $\mathrm{V}$, accounted for $84 \%$ of its variation. Resulting models of percentage moisture $\left(R^{2}=0.79\right)$, percentage lean mass $\left(R^{2}=0.79\right)$, percentage fat $\left(R^{2}=0.79\right)$, and fat mass $\left(R^{2}=0.87\right)$ were obtained using $R s D$ and $V$. Furthermore, the values of RsD regarding $V$, and PA in the prediction models accounted for $91 \%$ and $89 \%$ of variation in protein mass and lean mass, respectively. Bioimpedance analysis proved to be an efficient method to estimate the body composition of lambs slaughtered at different body mass stages.

Keywords: sheep, lean mass, carcass composition, impedance, resistance

\section{Introduction}

Sheep farming is an essential economic activity in many countries especially the poorest ones (Herrero et al., 2013). However, recent sheep meat consumption patterns are in line with current market trends indicating that increased sheep meat consumption depends on the final product quality to satisfy a higher purchasing power in emerging economies (Sepúlveda, Maza, \& Pardos, 2011; Shackelford, Leymaster, Wheeler, \& Koohmaraie, 2012). Therefore, to develop the lamb production sector to reach its full potential farmers need to be more efficient, achieve economies of scale as well as consider engaging in producing certified lamb to fulfil market demand. As a result, more integration among all links of the production chain is required in order to achieve the consolidation of sheep farming aimed at quality meat production (Ricardo et al., 2015). 
53 A solid understanding of tissue growth and tissue development rate that make up lamb

54 carcasses is extremely important, because from such information better strategic 55 management interventions could be considered in order to improve the desired market body tissue deposition. Besides, carcasses tend to be paid according to their quality, which is related to a greater lean mass percentage and minimal fat amount to satisfy market demand (Álvarez et al., 2013; della Malva et al., 2016; Font-i-Furnols \& Guerrero, 2014). The latter should be just enough to deliver the expected nutritional and organoleptic characteristics from sheep meat.

The evaluation of carcass composition using in vivo methodology allows firstly, for a better use of the factors of production, secondly, to determine the ideal age of slaughter, and, thirdly, to hopefully provide a uniform product for the meat processing industries. Furthermore, the use of in vivo body composition analysis also contributes to the reduction of error in carcass since classification tends to be subjective (Zollinger, Farrow, Lawrence, \& Latman, 2010).

In vivo bioimpedance analysis (BIA) is a simple, rapid, relatively cheap, non-destructive, and minimally invasive method to estimate the body composition of sheep (Altmann, Pliquett, Suess, \& Von Borell, 2004; Avril, Lallo, Mlambo, \& Bourne, 2013; Berg \& Marchello, 1994). Bioimpedance measures both modulus and phase of an equivalent impedance at a certain frequency, which is then calculated both resistance and reactance. Bioimpedance uses an alternating current (eg., $800 \mu \mathrm{A}$ at $50 \mathrm{kHz}$ ) which is injected into the biological material (Swantek, Crenshaw, Marchello, \& Lukaski, 1992). Furthermore, BIA may act as an estimator of body composition since it senses the difference in the conductivity between fat and fat-free mass (Lukaski et al., 1985). However, BIA is not a direct method to assess body composition and its accuracy, among other non-linearities, depends also on the precision of the chosen regression equations (Norman, Stobäus, Pirlich, \& Bosy-Westphal, 2012). The use of resistive and reactive densities to predict beef 
carcass composition has already been investigated (Zollinger et al., 2010). As far as our knowledge is concerned, the use of such predictors have not been used in lambs. The objective of this study was to evaluate the potentiality of in vivo bioimpedance analysis to estimate body composition in lambs at different ages of slaughter.

\section{Material and methods}

The research was conducted at the Laboratory of Sheep of the Department of Animal Science of the Federal University of Santa Maria (UFSM), Santa Maria, RS, Brazil, after being approved by the Ethics Committee on Animal Trials of this University, under the protocol \#8259211015. All handling from the lamb rearing until their slaughter and laboratory analyzes were carried out within the Sheep Laboratory confines.

\subsection{Animals}

Thirty-one Texel and lle de France crossbred three-month old weaned ram lambs were used for the purpose of this research. The animals were marked, weighed and distributed into eight pens covered from the elements. They were distributed in groups according to similar weight but on average they had live weight of $19.7 \mathrm{~kg}$. The pens had slatted-floor and were equipped with feeders and water troughs. The animals were fed ad libitum and the amount of feed was adjusted in order to keep the leftover food at around $10 \%$ of the total amount given.

A balanced diet calculated according to the NRC (2007) guidelines was administered to the animals in order for them to gain $0.200 \mathrm{Kg} /$ day. The formulation based on dry matter accounted for the $30: 70$ ratio alfafa hay:concentrate $(37.9 \%$ of maize grain, $14.4 \%$ of soy 
105

106

107

108

109

110

111

112

113

114 A single-frequency BIA equipment (Model RJL Quantum II Bioelectrical Body Composition

116

117

118

119

120

121

122

123

124

125

126

127

128

129

130

bran, $16.4 \%$ of wheat bran, and $1.27 \%$ of calcitic lime). The mineral mixture was supplied ad libitum in separated feeders. Weight measurements took place at weekly intervals until they reached pre-established slaughter weights of $20,26,32$, or $38 \mathrm{~kg}$. Before the slaughter of the animals, body weight (BW) (kg) was recorded (after 14 hours of fasting of solids), body length $(\mathrm{BL})(\mathrm{cm})$ was measured (from the last cervical vertebrae to the first sacral vertebrae), and the BIA readings were taken.

\subsection{Bioimpedance measurements}

Analyzer) was used to make the measurements. This apparatus injects an alternating electrical current of $800 \mu \mathrm{A}$ at $50 \mathrm{kHz}$ into the different body tissues by using two electrodes and then measures the voltage resultant across other two electrodes. The equipment is connected by four cables that are attached to the electrodes by color-coded electric clips. The black and red electrodes were configured as current transmitters and current detectors, respectively. Stainless steel acupuncture needles with spiral cable $(0.40$ x $15 \mathrm{~mm}$ ) were used as electrodes. They were inserted into the animal muscle at a standard depth just to make a good electrode contact in all body tissues (Berg \& Marchello, 1994).

Data were collected following the methodology proposed by Jenkins, Leymaster, and Turlington (1988) and adapted for live lambs. During data collection, the lambs were initially contained with an insulating rope tied to their feet, in order to keep them immobile without the need of use of anesthetics. Then, they were laid on plastic tarpaulin for insulating them from any contact with the ground, preventing leakage current. The animals were positioned on their right side (lateral decubitus) and a small area of the animal wool was shaven off in a straight line on the central region of the lateral face of the leg region 
131 (rear limb) and forearm region (front limb). The distal transmitter electrodes were attached

132 onto the extensor muscle complex of the front and rear limbs, approximately $3.0 \mathrm{~cm}$

133 proximal to the carpal and tarsal articulations, respectively. The proximal detector

134 electrodes were inserted $10 \mathrm{~cm}$ from the transmitter ones, caudal to the knee region (rear

$135 \operatorname{limb}$ ) and cranial to the elbow region (front limb) (Fig. 1).

136 Both resistance (Rs) $(\Omega)$ and reactance $(\mathrm{Xc})(\Omega)$ were measured once for each animal,

137 then values of conductance $(C)$ and impedance $(Z)$ were calculated by using the formulas

138 described by Lukaski, Johnson, Bolonchuk, and Lykken (1985), where $C=1 /$ Rs $(\Omega)$ and $Z$

$139=\left(\mathrm{Rs}^{2}+\mathrm{Xc}^{2}\right)^{0.5}(\Omega)$. The relationship between resistance and reactance values results in an

140 angle, which is defined as phase angle (PA) $\left({ }^{\circ}\right)$. The PA was directly calculated as the arc

141 tangent of the ratio of reactance and resistance, where $P A=\tan ^{-1}(\mathrm{Xc} / \mathrm{Rs})$, expressed in

142 radians. To convert the results into degrees, the PA values were then multiplied by $180 \% \pi$

143 as described by Lukaski (2013).

144 The body bioelectrical volume (V) was obtained by the relationship between animal body

145 length and resistance, where $\mathrm{V}=\mathrm{BL} 2 / \mathrm{Rs}\left(\mathrm{cm}^{2} / \Omega\right)$, adapted from Jenkins et al. (1988). Both

146 resistive $(\mathrm{RsD})$ and reactive density $(\mathrm{XcD})$ were also calculating according to Zollinger et

147 al. (2010). They proposed to replace the half carcass weight by body weight as well as

148 replacing the distance between the electrodes by the body length of the animals.

149 Therefore, the final formula used in this work is as it follows: $\mathrm{RsD}=\mathrm{BW}{ }^{2} /\left(\mathrm{BL}^{2} / \mathrm{Rs}\right)\left(\mathrm{kg}^{2} / \mathrm{cm}^{2}\right.$

$150 \Omega)$ and $\mathrm{XcD}=\mathrm{BW}^{2} /\left(\mathrm{BL}^{2} / \mathrm{Xc}\right)\left(\mathrm{kg}^{2} / \mathrm{cm}^{2} \Omega\right)$.

151

$152 \quad 2.3$ Laboratory analyses

153

154 After the slaughter, the carcasses were weighed and stored in a chilling chamber at a

155 temperature of $2^{\circ} \mathrm{C}$. After 24 hours, they were weighed for a second time in order to obtain

156 the cold carcass weight $(\mathrm{CCW})(\mathrm{kg})$. The carcasses were longitudinally split into two half 
carcasses and the right half carcasses were weighed and divided into four regional cuts;

158 neck, shoulder, ribs, and leg. These cuts were boned in order to obtain the soft tissue

159 mass of the half carcasses, which are composed basically by muscles, fat, blood vessels,

160 nerves, and connective tissue. The soft tissue mass obtained from each cut was ground,

161 homogenized, and approximately $200 \mathrm{~g}$ of representative sample were extracted for

162 laboratory analyses. Four samples from each carcass were analyzed in duplicates.

163 Moisture (930.15), protein (992.15), and ash (942.05) were determined in these samples

164 according to the methodology described on AOAC International (1995). Fat was

165 determined according to the method proposed by Bligh and Dyer (1959). The chemical

166 composition determined in each cut was used to calculate the weight and the proportion of

167 each chemical component of the half carcass and adjusted to the cold carcass weight. The

168 weight and percentage of the lean mass was obtained by the sum of weight and

169 percentage, respectively, of protein and moisture of the carcass soft tissue, then Lean

170 mass $(\mathrm{kg})=$ protein $(\mathrm{kg})+$ moisture $(\mathrm{kg})$ and Lean mass $(\%)=$ protein $(\%)+$ moisture $(\%)$,

171 according to Jenkins et al. (1988).

172

$173 \quad 2.4$ Statistical analysis

174

175 Multiple regression analyses were performed using the lamb carcass composition as

176 dependent variables (weight and percentage of moisture, protein, fat, and lean mass) and

177 bioimpedance measurements as independent variables (resistance, reactance,

178 conductance, phase angle, body bioelectrical volume, resistive density, and reactive

179 density). The body weight and body length of the animals were only used to calculate V,

$180 \mathrm{RsD}$, and $\mathrm{XcD}$. The normality of the data was presumable based on the central limit

181 theorem, which considers an acceptable normal distribution with 30 or more observations.

182 Correlation coefficients between the BIA measurements and the carcass composition were 
183 determined. Stepwise regression was used to eliminate the variables that did not increase

184 the prediction power of the model. Those variables that did not significantly contribute to 185 the model $(P>0.05)$ were eliminated. The biostatistical models were selected which 186 presented the highest coefficient of determination $\left(R^{2}\right)$, lowest root mean square error

187 (RMSE), and the Mallows Cp statistic (Cp) closest to the number of parameters included in 188 the model.

189 The best regression models were evaluated by cross-validation according to the following 190 procedure, which was the same for each model. Briefly, from the complete dataset, one

191 animal was selected and regression parameters were estimated with data of the remaining $192 n-1$ animals. Values of weight and percentage of moisture, protein, fat, and lean mass 193 were predicted for the selected animal by this regression function. Then, the squared 194 difference between the predicted and measured chemical compounds of the selected 195 animal was calculated. This procedure was repeated for every animal. The mean of the $n-$ 196 squared differences between the predicted and measured carcass compounds of all $n$ 197 animals was calculated to obtain the mean squared error of the predicted weight and 198 percentage of moisture, protein, fat, and lean mass. Precision and accuracy of the equations were measured by evaluating the highest coefficient of determination $\left(R^{2}\right)$, the lowest root mean squared error (RMSE), the mean prediction error (MPE), and relative mean prediction error (RMPE; \%) of the cross-validation. The statistical software SAS 202 (SAS University Edition, 2017) was used for all statistical analyses.

\section{Results}

205 
208 The descriptive statistics of linear measurements and bioimpedance assessments in

209 lambs are shown in Table 1. The body weight presented a larger variation range than body 210 length. The minimum and maximum resistance readings ranged from 60 to $110 \Omega$, while 211 the reactance variation was from 6 to $15 \Omega$. Body bioelectrical volume, resistive density, 212 and reactive density, which used weight and/or length values in their formulas, had larger 213 variation than resistance and reactance alone.

214 The mean values, range, and variability of carcass linear measurements and lamb body 215 composition are shown in Table 2. The weight of cold carcass and soft tissue had great 216 variation between the minimum and maximum values. The same can be observed with the 217 mass of the lamb body components. When the body composition was expressed in 218 percentage values, fat content showed to present the largest variation, ranging from 8.39 219 to $26.9 \%$.

\subsection{Correlations}

223 The results of the correlations between BIA measurements and chemical analyses of the 224 lamb carcasses are presented in Table 3. The mass of body chemical constituents 225 increased with the increase in $\mathrm{BL}, \mathrm{BW}, \mathrm{PA}, \mathrm{V}, \mathrm{RsD}$, and $\mathrm{XcD}$. Although fat percentage also 226 increased, in contrary, protein, moisture, and lean mass percentages decreased. The 227 relationship between $\mathrm{BL}$ and/or BW with Rs or Xc may have affected the stronger 228 correlations between $\mathrm{V}, \mathrm{RsD}$, and $\mathrm{XcD}$ and the lamb body composition. Protein 229 percentage was an exception because it was not significantly correlated to any BIA 230 variables $(P>0.05)$.

\subsection{Prediction Models}


234 The final predictive models of the lamb body composition are shown in Table 4. The 235 amount of moisture was mostly explained by the $\mathrm{XcD}\left(\mathrm{R}^{2}=0.56 ; \mathrm{Cp}=93.3\right)$. When $\mathrm{V}$ was 236 included in this model, they accounted for $84 \%$ of its variation on lamb carcass, and the Cp 237 value decreased to 17.6. Regarding protein and fat mass predictive models, the use of $238 \mathrm{RsD}$ alone explained most of the variation of these components on carcass, $62 \%$ and $23970 \%$, respectively. When $\mathrm{V}$ was added to the models, their prediction power improved $\left(\mathrm{R}^{2}\right.$ $240=0.89$ and $\left.R^{2}=0.87\right)$ and the $C p$ values decreased from 87.3 and 41.2 to 9.04 and 3.56, 241 respectively. Furthermore, to estimate the protein content of the samples the PA value was 242 then added to the protein equation. The PA value together with RsD and V explained $91 \%$ 243 of protein variation on carcass. From these results, it is possible to note that predictive 244 models for protein mass and fat mass are more precise than the one for moisture mass.

245 Resistive density, alone, accounted for $63 \%$ of variation of moisture, fat, and lean mass 246 percentages on lamb carcass. When $\mathrm{V}$ was added to these models, there was an increase 247 of $16 \%$ in their coefficients of determination. Furthermore, the $\mathrm{Cp}$ values decreased from $24820.5,25.3$, and 25.1 to $2.32,4.70$, and 4.56, respectively. However, none of the BIA 249 variables contributed significantly $(P>0.05)$ to the prediction of protein percentage. This 250 fact may be explained due to the little variation in protein percentage on lamb carcass $251 \quad(18.9 \pm 0.12 \%)($ Table 2$)$.

252 The lean mass model was initially mostly explained by $X c D\left(R^{2}=0.56\right)$. Afterwards, $V$ was 253 added to the model, which increased the prediction power in $28 \%$. Thereafter, the addition 254 of $\mathrm{RsD}$ enhanced $\mathrm{R}^{2}$ by $2 \%$. Using the Stepwise procedure, when RsD was added to the 255 model, it was observed that XcD stopped contributing to the prediction power of the model 256 and, therefore, it was removed from the equation. Besides, when PA was added to that 257 model, it accounted for $89 \%$ of the variation of the lean mass on lamb carcass. The 258 prediction power of these equations can be observed by the statistic results of the cross259 validation. Regarding the $\mathrm{R}^{2}$ of the cross-validation, the models for predicting the mass of 
260

261

262 263 264

moisture, protein, fat, and lean mass presented good precision with $R^{2}$ of $0.93,0.95,0.91$ and 0.93 , respectively. Although the prediction models of the percentage of moisture, fat, and lean mass resulted in a lower $\mathrm{R}^{2}$ compared to the absolute values, they also had an acceptable prediction power with $R^{2}$ of $0.86,0.88$, and 0.88 , respectively.

\section{Discussion}

The lamb body development is typically understood as an increase in mass. Growth rates of different tissues which compound the animal carcass are influenced by many factors such as genetics, age, and nutrition (Owens, Dubeski, and Hansont, 1993). Nonetheless, the lamb body shape change over time, especially before they reach maturity, indicating they tend to take longer to grow (in centimeters) than to gain weight (in kilograms). That could be confirmed in the sample because body weight varied more than body length (Table 1).

The carcass composition can be expressed in either mass or percentage. As the increase of body weight at slaughter increases the weight of cold carcass, consequently the weight of each body compound also increases with a heavier carcass. Body composition when expressed in percentages shows that as the carcass fat content increases, the lean mass content decreases. The protein percentage had the smallest variation in the carcasses (Table 2). The small variation in protein percentage is a limitation in the prediction using the bioimpedance method.

The results of this study indicate that the electrical properties of lamb body tissues were affected by their body composition, whereas longer and heavier animals, with more body fat deposits presented higher BIA values than smaller and lighter ones (Table 3). Due to the fact that it was performed a four electrode impedance measurement, as known by transfer impedance, this agrees with the bioimpedance principle as, it depends on the 
electrode geometry, volume and length of the biological conductor material, and on the

287 frequency of the applied current (Berg \& Marchello, 1994; Lukaski et al., 1985; Swantek, 288 Crenshaw, Marchello, \& Lukaski, 1992). Electrode material, distance between electrodes, 289 and the place where they are insert also influence BIA measurements. Therefore, BIA reproducibility depends on the electrode placement.

291 The body volume of lambs is composed of intra- and extracellular fluids that behave as 292 heterogeneous electrical conductors with cell membranes working as electrical capacitors, 293 and body fat acting as an insulator material and generating electrical resistance (Altmann 294 et al., 2004; Swantek et al., 1992). For humans, this volume is obtained by the relationship 295 between the squared height and resistance (Lukaski et al., 1985). However, in lambs, 296 Jenkins et al. (1988) replaced the height by carcass length. Then Berg and Marchello 297 (1994) replaced it by the conductor length (distance between current detector electrodes). 298 Regardless of how the volume was obtained, it is needed to estimate the body 299 composition of lambs. This fact was evidenced in this study since this variable was 300 selected in the prediction models for both mass and percentage of the lamb body 301 components (Table 4).

302 Reactance is the property of storing alternating electrical energy under the form of an 303 electric field. It is related to the dynamic performance of cell membranes, which work as an 304 electrical capacitor (Swantek et al., 1992). The cell membrane capacitance can be used as 305 an indicator of lean mass and intracellular body mass, and it is also related to extra- and 306 intracellular hydric balance (Altmann et al., 2004). This fact may explain the model 307 selection of volume and reactive density to estimate the water amount on lamb carcass 308 (Table 4). The reactive density explained $56 \%$ of the variation of lean mass on lamb 309 carcasses. This might be due to the large amount of moisture $(65.4 \%$ in average $)$ in the 310 soft tissue mass of the lamb carcasses (Table 2). The negative correlations obtained 
311 between $\mathrm{XcD}$ and moisture, protein, and lean mass percentages reinforce this fact (Table $3123)$.

313 The resistive part of the impedance can be attributed to the opposition of a current flow 314 through intra- and extracellular ions inside the tissue (Lukaski, 2013), which can be directly 315 correlated to the difference in conductivity between fat and lean mass (Jenkins et al., 316 1988). Hence, Rs is directly related to the body hydration level and body fat. Animals with 317 a larger percentage of fat in the carcass present smaller body water percentage and 318 higher resistance to the applied current. As the mass of carcass components increases, 319 there is an increment in body weight and in some BIA variables like PA, V, RsD, and $X c D$ 320 (Table 3). These increases were also related to an increase of fat percentage, but to 321 decreased moisture, protein, and lean mass percentages on lamb carcasses (Table 3). 322 According to Owens, Dubeski, and Hansont (1993), changes in body composition are 323 expected since they naturally occur throughout the physiological maturity of the lambs. 324 Based on these results it is possible to note a significant efficiency of BIA in detecting 325 these changes in body composition of lambs slaughtered at different body masses. 326 According to Zollinger et al. (2010), who assessed BIA in beef cattle carcasses, RsD and 327 XcD decreased with the increase of lean mass, and increased with the increase of fat 328 percentage on carcass. This indicates a strong relationship of $\mathrm{RsD}$ and $\mathrm{XcD}$ with lean 329 mass and fat body contents.

330 The phase angle was another important variable used in this work, which was obtained by 331 the relationship between resistance and reactance values. The PA may vary from zero 332 (eg., medium without cell membranes) to 90 degrees (eg., a medium full of cell 333 membranes but no fluids) (Lukaski, 2013). This angle depends on the capacitance due to 334 the cell membranes and, in humans, it is a marker of amount and quality of soft tissue 335 mass, as well as body hydration status (Norman et al., 2012). Therefore, its variation 336 indicates changes in body composition, especially for protein and lean mass. 
337 Predictive models for body composition need to be accurate in order to become suitable to

338 farmers. Therefore, Mallows Cp statistic is considered a robust tool for predictive model 339 selection. The $\mathrm{Cp}$ value that is closest to the number of parameters included in the model 340 indicates less biased estimates and, therefore, a more precise model. Similar to what Berg 341 and Marchello (1994) found, this study identified some possible outliers which were not 342 removed from the database given the difficulty of identifying the origin of the error.

343 Removal of these outliers could also improve the results from the statistical analysis.

344 On the one hand, the predictive models for mass of body constituents presented higher $\mathrm{R}^{2}$ 345 and lower RMSE values when compared to their respective percentages, and therefore, 346 greater precision. On the other hand, if the $\mathrm{Cp}$ value is considered, the moisture 347 percentage and lean mass percentage presented a higher precision to estimate the real 348 regression coefficients and predict future answers than their absolute masses. Likewise, 349 considering these statistical parameters, it is possible to note that predictive models for 350 protein mass and fat mass are more precise than the one for moisture mass (Table 4).

351 Regarding the cross-validation, the RMPE values for predicting fat, both in absolute and 352 relative values, were higher than the other carcass components. The RMPE values for 353 predicting the absolute carcass compounds were also higher comparing to the relative 354 ones. This may be due to the higher variation range of the values expressed in grams 355 related to those presented as percentage. Nevertheless, concerning the $\mathrm{R}^{2}$ of the cross356 validation, the absolute values of the lamb carcass components had the highest accuracy. 357 These findings indicate that the models obtained for predicting lamb carcass composition 358 are quite robust.

\section{Conclusion}


362 Bioimpedance is an efficient method to estimate the carcass composition of lambs 363 slaughtered at different body masses. The use of resistive and reactive densities data 364 improved the results of in vivo bioimpedance analysis used to assess the lamb body 365 composition. This might be the case of measuring lamb body composition in order to 366 reduce errors related to subjectivity.

\section{Conflict of interests}

There is no conflict of interests involved in this work.

\section{Acknowledgments}

To the Coordenação de Aperfeiçoamento de Pessoal de Nível Superior (CAPES) for the scholarship granted to the first author. We are also very grateful to Pedro Bertemes-Filho,

Professor at Universidade do Estado de Santa Catarina, Brazil, as a consulting reviewer 377 for this article.

\section{References}

Altmann, M., Pliquett, U., Suess, R., \& Von Borell, E. (2004). Prediction of lamb carcass composition by impedance spectroscopy. Journal of Animal Science, 82(3), 816-825.

384 Álvarez, J. M., Rodríguez Iglesias, R. M., García Vinent, J., Giorgetti, H., Rodríguez, G., \& Baselga, M. (2013). Introduction of sheep meat breeds in extensive systems: Lamb carcass characteristics. Small Ruminant Research, 109(1), 9-14. https://doi.org/10.1016/j.smallrumres.2012.08.001 
AOAC International. (1995). Official Methods of Analysis of AOAC International. Official Methods of Analysis of the Association of Official Analytical Chemists international (16th ed.). Washington, DC: AOAC International.

Avril, D. H., Lallo, C., Mlambo, V., \& Bourne, G. (2013). The application of bioelectrical impedance analysis in live tropical hair sheep as a predictor of body composition upon slaughter. Tropical Animal Health and Production, 45(8), 1803-1808. https://doi.org/10.1007/s11250-013-0438-8

Berg, E. P., \& Marchello, M. J. (1994). Bioelectrical impedance analysis for the prediction of fat-free mass in lambs and lamb carcasses. Journal of Animal Science, 72(2), 322329. https://doi.org//1994.722322x

Bligh, E. G., \& Dyer, W. J. (1959). A rapid method of total lipid lipid extraction and purification. Canadian Journal of Biochemistry and Physiology. 37(8), 911-917. https://doi.org/10.1139/o59-099

della Malva, A., Albenzio, M., Annicchiarico, G., Caroprese, M., Muscio, A., Santillo, A., \& Marino, R. (2016). Relationship between slaughtering age, nutritional and organoleptic properties of Altamurana lamb meat. Small Ruminant Research, 135, 39-45. https://doi.org/10.1016/j.smallrumres.2015.12.020

Font-i-Furnols, M., \& Guerrero, L. (2014). Consumer preference, behaviour and perception about meat and meat products: an overview. Meat Science, 98, 361-371. https://doi.org/10.1016/j.meatsci.2014.06.025

Herrero, M., Grace, D., Njuki, J., Johnson, N., Enahoro, D., Silvestri, S., \& Rufino, M. C. (2013). The roles of livestock in developing countries. Animal, 7(s1), 3-18. https://doi.org/10.1017/S1751731112001954

Jenkins, T. G., Leymaster, K. A., \& Turlington, L. M. (1988). Estimation of fat-free soft tissue in lamb carcasses by use of carcass and resistive impedance measurements. Journal of Animal Science, 66(9), 2174-2179. 
Lukaski, H. C. (2013). Evolution of bioimpedance: A circuitous journey from estimation of physiological function to assessment of body composition and a return to clinical research. European Journal of Clinical Nutrition, 67, S2-S9. https://doi.org/10.1038/ejcn.2012.149

Lukaski, H. C., Johnson, P. E., Bolonchuk, W. W., \& Lykken, G. I. (1985). Assessment of fat-free mass using bioelectrical impedance measurements of the human body. American Journal of Clinical Nutrition, 41(4), 810-817.

Norman, K., Stobäus, N., Pirlich, M., \& Bosy-Westphal, A. (2012). Bioelectrical phase angle and impedance vector analysis - Clinical relevance and applicability of impedance parameters. Clinical Nutrition, 31(6), 854-861. https://doi.org/10.1016/j.clnu.2012.05.008

National Research Council - NRC. Nutrient requirements of small ruminants: Sheep, goats, cervids, and new world camelids. Washington, D.C.: National Academy Press, 2007. 384p.

Owens, F. N., Dubeski, P., \& Hansont, C. F. (1993). Factors that alter the growth and development of ruminants. Journal of Animal Science, 71(11), 3138-3150. https://doi.org//1993.71113138x

Ricardo, H. A., Fernandes, A. R. M., Mendes, L. C. N., Oliveira, M. A. G., Protes, V. M., Scatena, E. M., ... Alves, L. G. C. (2015). Carcass traits and meat quality differences between a traditional and an intensive production model of market lambs in Brazil: Preliminary investigation. Small Ruminant Research, 130, 141-145. https://doi.org/10.1016/j.smallrumres.2015.07.007

SAS University Edition (2017). SAS Studio 2.5 9.4M4. SAS Institute Inc, Cary, NC.

Sepúlveda, W. S., Maza, M. T., \& Pardos, L. (2011). Aspects of quality related to the consumption and production of lamb meat. Consumers versus producers. Meat 
441 Shackelford, S. D., Leymaster, K. A., Wheeler, T. L., \& Koohmaraie, M. (2012). Effects of 442 breed of sire on carcass composition and sensory traits of lamb. Journal of Animal 443 Science, 90(11), 4131-4139. https://doi.org/10.2527/jas.2012-5219

444 Swantek, P. M., Crenshaw, J. D., Marchello, M. J., \& Lukaski, H. C. (1992). Bioelectrical 445 impedance: a nondestructive method to determine fat-free mass of live market swine 446 and pork carcasses. Journal of Animal Science, 70(1), 169-177. $447 \quad$ https://doi.org/10.2527/1992.701169x

448 Zollinger, B. L., Farrow, R. L., Lawrence, T. E., \& Latman, N. S. (2010). Prediction of beef 449 carcass salable yield and trimmable fat using bioelectrical impedance analysis. Meat $450 \quad$ Science, 84(3), 449-454. https://doi.org/10.1016/j.meatsci.2009.09.015 


\section{Table 1}

454 Descriptive statistics of body characteristics and bioimpedance assessments on lambs.

\begin{tabular}{lcccccc}
\hline & $\mathrm{n}^{1}$ & Min $^{2}$ & Max $^{3}$ & Mean & SD $^{4}$ & SEM $^{5}$ \\
\hline Body weight, $\mathrm{kg}$ & 31 & 18.1 & 38.6 & 27.9 & 5.48 & 0.98 \\
Body length, $\mathrm{cm}$ & 31 & 47.0 & 64.0 & 55.8 & 4.76 & 0.85 \\
Resistance, $\Omega$ & 31 & 60.0 & 110.0 & 87.7 & 11.9 & 2.14 \\
Reactance, $\Omega$ & 31 & 6.00 & 15.0 & 10.4 & 2.33 & 0.42 \\
Conductance, $\Omega$ & 31 & 0.01 & 0.02 & 0.01 & 0.00 & 0.00 \\
Impedance, $\Omega$ & 31 & 60.3 & 111.0 & 88.3 & 12.0 & 2.16 \\
Phase angle, ${ }^{\circ}$ & 31 & 4.81 & 8.60 & 6.70 & 1.03 & 0.18 \\
Body bioelectrical volume, $\mathrm{cm}^{2} / \Omega$ & 31 & 24.5 & 58.2 & 36.5 & 8.45 & 1.52 \\
Resistive density, $\mathrm{kg}^{2} / \mathrm{cm}^{2} \Omega$ & 31 & 9.05 & 41.6 & 22.1 & 7.06 & 1.27 \\
Reactive density, $\mathrm{kg}^{2} / \mathrm{cm}^{2} \Omega$ & 31 & 0.82 & 5.61 & 2.64 & 1.06 & 0.19 \\
\hline
\end{tabular}

$455{ }^{1} \mathrm{n}=$ number of lambs, ${ }^{2} \mathrm{Min}=$ Minimum, ${ }^{3} \mathrm{Max}=$ Maximum, ${ }^{4} \mathrm{SD}=$ Standard deviation, ${ }^{5} \mathrm{SEM}=$ 456 Standard error of mean.

457 


\section{Table 2}

459 Descriptive statistics of carcass characteristics and body composition of lambs.

\begin{tabular}{lcccccc}
\hline & $\mathrm{n}^{1}$ & Min $^{2}$ & Max $^{3}$ & Mean & SD $^{4}$ & ${ }^{5}$ SEM \\
\hline Cold carcass weight, kg & 31 & 6.36 & 17.4 & 11.9 & 2.94 & 0.53 \\
Soft tissue mass weight, kg & 31 & 5.07 & 14.6 & 9.71 & 2.58 & 0.46 \\
Moisture, kg & 31 & 3.55 & 8.59 & 6.26 & 1.35 & 0.24 \\
Moisture, \% & 31 & 54.0 & 72.2 & 65.4 & 4.03 & 0.72 \\
Ash, kg & 31 & 0.05 & 0.13 & 0.09 & 0.02 & 0.00 \\
Ash, \% & 31 & 0.59 & 1.14 & 0.91 & 0.12 & 0.02 \\
Protein, kg & 31 & 0.98 & 2.65 & 1.83 & 0.47 & 0.08 \\
Protein, \% & 31 & 18.0 & 20.8 & 18.9 & 0.69 & 0.12 \\
Fat, kg & 31 & 0.49 & 3.61 & 1.53 & 0.83 & 0.15 \\
Fat, \% & 31 & 8.39 & 26.9 & 14.8 & 4.40 & 0.79 \\
Lean mass, kg & 31 & 4.53 & 11.1 & 8.09 & 1.81 & 0.32 \\
Lean mass, \% & 31 & 72.3 & 90.6 & 84.3 & 4.32 & 0.78 \\
\hline
\end{tabular}

$460{ }^{1} \mathrm{n}=$ number of lambs, ${ }^{2}$ Min $=$ Minimum, ${ }^{3}$ Max $=$ Maximum, ${ }^{4} \mathrm{SD}=$ Standard deviation, ${ }^{5} \mathrm{SEM}=$ 461 Standard error of mean. 


\section{Table 3}

464 Simple Pearson correlations between body characteristics and bioimpedance assessments to lamb body composition.

\begin{tabular}{|c|c|c|c|c|c|c|c|c|c|c|}
\hline & $\begin{array}{c}\mathrm{BW}^{1}, \\
\mathrm{~kg}\end{array}$ & $\begin{array}{l}\mathrm{BL}^{2} \\
\mathrm{~cm}\end{array}$ & $\begin{array}{c}\mathrm{Rs}^{3} \\
\Omega\end{array}$ & $\begin{array}{c}\mathrm{Xc} \\
\Omega\end{array}$ & $\begin{array}{c}\mathrm{C}^{5} \\
\Omega\end{array}$ & $\begin{array}{c}Z^{6} \\
\Omega\end{array}$ & $\underset{0}{\mathrm{PA}^{7}}$ & $\begin{array}{c}\mathrm{V}^{8} \\
\mathrm{~cm}^{2} / \Omega\end{array}$ & $\begin{array}{c}\mathrm{RsD}^{9} \\
\mathrm{~kg}^{2} / \mathrm{cm}^{2} \Omega\end{array}$ & $\begin{array}{c}\mathrm{XcD^{10 }} \\
\mathrm{kg}^{2} / \mathrm{cm}^{2} \Omega\end{array}$ \\
\hline Moisture, kg & $0.93^{* * *}$ & $0.70^{* * *}$ & -0.07 & 0.33 & 0.05 & -0.06 & $0.51^{* *}$ & $0.54^{* *}$ & $0.75^{* * *}$ & $0.75^{* * *}$ \\
\hline Moisture, \% & $-0.85^{* * *}$ & $-0.59^{* * *}$ & -0.05 & -0.31 & 0.03 & -0.05 & $-0.37^{*}$ & $-0.40^{*}$ & $-0.79^{\star * *}$ & $-0.77^{\star * *}$ \\
\hline Protein, kg & $0.95^{* * *}$ & $0.70^{* * *}$ & -0.04 & 0.34 & 0.02 & -0.03 & $0.50^{* *}$ & $0.52^{* *}$ & $0.79^{* * *}$ & $0.78^{* * *}$ \\
\hline Protein, \% & -0.33 & -0.25 & 0.02 & -0.02 & -0.04 & 0.02 & -0.01 & -0.21 & -0.32 & -0.28 \\
\hline Fat, kg & $0.90^{* * *}$ & $0.62^{\star * *}$ & 0.05 & 0.32 & -0.04 & 0.05 & $0.39^{*}$ & $0.42^{*}$ & $0.84^{* * *}$ & $0.81^{* * *}$ \\
\hline Fat, \% & $0.85^{* * *}$ & $0.59^{* * *}$ & 0.04 & 0.30 & -0.02 & 0.05 & $0.36^{*}$ & $0.40^{*}$ & $0.79^{* * *}$ & $0.77^{* * *}$ \\
\hline Lean mass, kg & $0.94^{* * *}$ & $0.70^{* * *}$ & -0.06 & 0.33 & 0.04 & -0.05 & $0.51^{* *}$ & $0.54^{* *}$ & $0.76^{\star * *}$ & $0.76^{\star * *}$ \\
\hline Lean mass, \% & $-0.85^{\star * *}$ & $-0.59^{\star * *}$ & -0.04 & -0.29 & 0.02 & -0.05 & -0.35 & $-0.41^{*}$ & $-0.79^{\star \star *}$ & $-0.76^{\star * *}$ \\
\hline
\end{tabular}

$467 * P<0.05$.

$468 * * P<0.01$

$469 * * * P<0.001$. 


\section{Table 4}

472 Predicting models of lamb body composition by in vivo bioimpedance analysis.

\begin{tabular}{|c|c|c|c|c|c|c|c|c|c|c|}
\hline & \multirow{2}{*}{ Models } & \multicolumn{4}{|c|}{ Calibration } & \multicolumn{5}{|c|}{ Cross-validation } \\
\hline & & $\mathrm{R}^{2 a}$ & RMSE $^{b}$ & $C p^{c}$ & $P$-value & $\mathrm{R}^{2 a}$ & RMSE $^{\mathrm{b}}$ & MPE $^{d}$ & $\mathrm{RMPE}^{\mathrm{e}}, \%$ & $P$-value \\
\hline Moisture, $\mathrm{kg}$ & $Y=0.66+0.94 X c D+0.09 V$ & 0.84 & 0.55 & 17.6 & $<0.0001$ & 0.93 & 0.50 & 0.43 & 7.47 & $<0.0001$ \\
\hline Moisture, \% & $Y=82.2-0.45 R s D-0.19 V$ & 0.79 & 1.92 & 2.32 & $<0.0001$ & 0.86 & 2.59 & 1.82 & 2.78 & $<0.0001$ \\
\hline Protein, $\mathrm{kg}$ & $Y=-0.70+0.05 R s D+0.03 V+0.07 P A$ & 0.91 & 0.15 & 5.32 & $<0.0001$ & 0.95 & 0.15 & 0.12 & 6.97 & $<0.0001$ \\
\hline Fat, $\mathrm{kg}$ & $Y=-2.11+0.10 R s D+0.04 V$ & 0.87 & 0.30 & 3.56 & $<0.0001$ & 0.91 & 0.39 & 0.29 & 20.9 & $<0.0001$ \\
\hline Fat, \% & $Y=-3.69+0.49 R s D+0.21 V$ & 0.79 & 2.09 & 4.70 & $<0.0001$ & 0.88 & 2.66 & 1.76 & 12.5 & $<0.0001$ \\
\hline Lean mass, $\mathrm{kg}$ & $Y=-1.90+0.11 \mathrm{~V}+0.18 R \mathrm{RD}+0.31 P A$ & 0.89 & 0.64 & 10.3 & $<0.0001$ & 0.93 & 0.65 & 0.55 & 7.36 & $<0.0001$ \\
\hline Lean mass, $\%$ & $Y=102.5-0.48 R s D-0.21 \mathrm{~V}$ & 0.79 & 2.06 & 4.56 & $<0.0001$ & 0.88 & 2.65 & 1.75 & 2.05 & $<0.0001$ \\
\hline
\end{tabular}

$473 \quad{ }^{\mathrm{a}} \mathrm{R}^{2}=$ Coefficient of determination; ${ }^{\mathrm{b}} \mathrm{RMSE}=$ Root mean squared error; ${ }^{\mathrm{c}} \mathrm{Cp}=$ Mallows $\mathrm{Cp}$ statistic; ${ }^{\mathrm{d}} \mathrm{MPE}=$ Mean prediction error; ${ }^{\mathrm{e}} \mathrm{RMPE}=\mathrm{Relative}$ 474 mean prediction error.

$475 \mathrm{XcD}=$ reactive density, $\mathrm{V}=$ body bioelectric volume, $\mathrm{RsD}=$ resistive density, $\mathrm{PA}=$ phase angle. 


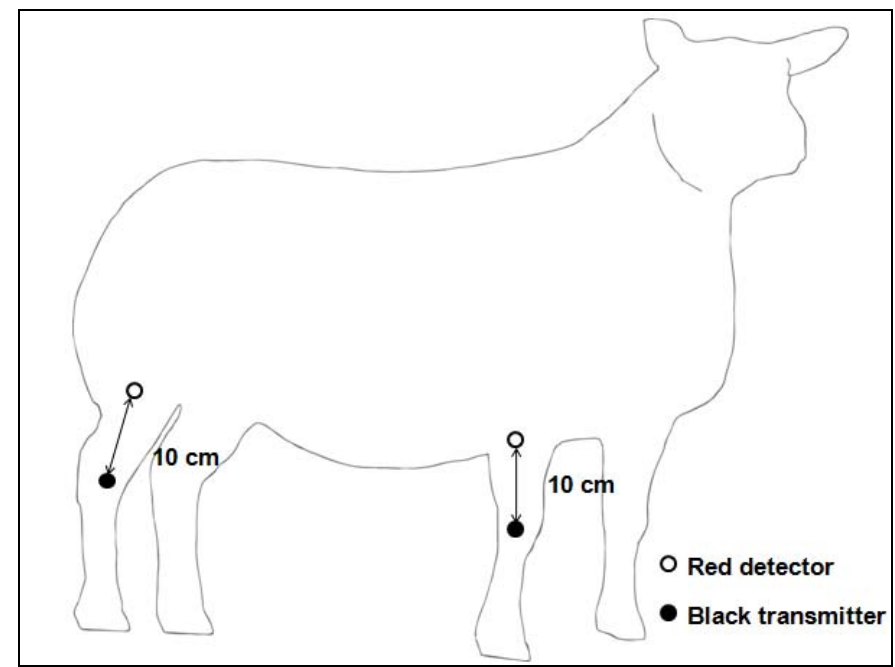

479

480

Fig. 1. Placement of transmitter and detector electrodes in live lambs for resistance 481 and reactance measurements. 